Article

\title{
Energy Efficiency at the Base of the Pyramid: A System-Based Market Model for Improved Cooking Stove Adoption
}

\author{
Niklas Vahlne * and Erik O. Ahlgren \\ Department of Energy and Environment Division of Energy Technology, \\ Chalmers University of Technology, Göteborg 412 96, Sweden; E-Mail: erik.ahlgren@chalmers.se \\ * Author to whom correspondence should be addressed; E-Mail: Niklas.vahlne@chalmers.se; \\ Tel.: +46-31-772-1428; Fax: +46-31-772-3592.
}

External Editor: Marc A. Rosen

Received: 21 July 2014; in revised form: 24 October 2014 / Accepted: 20 November 2014 / Published: 28 November 2014

\begin{abstract}
A widespread dissemination of improved cooking stoves in the developing world can lead to considerable improvement of health, to reduced pressure on natural woody resources and to substantial reductions of emissions contributing to global warming. A number of programs have aimed to achieve such dissemination, while few of the programs have had any large-scale success. It has been suggested that a more commercial approach, as opposed to subsidized or freely distributed stoves, would achieve a higher level of success. However, a majority of the households that would benefit from an improved stove are poor and cannot afford the cost of the stove, especially if no monetary savings are possible from a more efficient fuel use, i.e., if the fuel used is collected biomass. The aim of this paper is to propose and evaluate a model that might overcome some of the barriers previous programs have experienced. The proposed model involves commercialization of collected fuels. The methods for evaluation include a qualitative assessment of the proposed model aided by the literature on improved cooking stove programs, fuel wood collection and fuel switching together with a quantitative simplistic model calculation of a hypothetical application of the proposed model principles, in order to assess its financial feasibility. The assessment indicates that the model would increase both households' incentives and means to purchase and use improved cooking stoves. Furthermore, the model could possibly be partly financed based on carbon credits achieved from the reduction of greenhouse gas emissions.
\end{abstract}

Keywords: ICS; fuel wood; biomass; rural; policy 


\section{Introduction}

Solid biomass continues to be the main fuel for a majority of households in rural areas in the developing world [1]. The biomass is usually combusted in open fires or in inefficient stoves. This leads to emissions that pose severe health risks [2,3]. The inefficient combustion also leads to the formation of compounds, such as methane $\left(\mathrm{CH}_{4}\right)$ and black carbon $(\mathrm{BC})$. $\mathrm{BC}$ is an aerosol becoming increasingly recognized as one of the main compounds contributing to global warming, although the mechanism is complex and the forcing varies regionally [4-8].

In Asia (excluding the Middle East and Russia), the annual amount of biomass used in residential applications is about 470 Mtoe. This equals about half of all coal used in the region for electricity generation. Excluding China, the figures are of the same order, 270 and 260 Mtoe, respectively. In Africa, in energy terms, the residential biomass use is about four times larger than the coal used for electricity production [9]. Hence, compared to other sources of primary energy, residential use of collected biomass constitutes a major share of the total energy demand in many countries. It is, however, utilized at very low conversion efficiencies. One option for increasing the efficiency of biomass utilization and to reduce emissions is the dissemination and use of improved cooking stoves (ICSs) [10].

There is evidence, both from studies of ICS programs [11] and from studies of rural fuel choices [12,13], that households in urban areas are more prone to adopt ICSs or start to use more modern fuels, such as liquefied petroleum gas (LPG). Urban households have fewer possibilities to collect fuel wood, implying that they are already to a large extent purchasing fuels. Hence, more efficient fuel utilization has direct economic gains. Furthermore, in an urban setting, occupation away from agriculture is more likely, implying a higher opportunity cost of time.

In rural areas, on the other hand, biomass fuels are generally, but not always, more readily available for collection, incomes are generally lower, and there are fewer income generating occupations. Hence, short-term incentives for increased energy efficiency of cooking are likely lower. Although it is sometimes pointed out that the potential long-term benefits from stove or fuel switching through health improvements and time savings in the end would lead to financial gains for the households [14], this may not be enough to convince households in the short term (many of these stoves demand comparatively large initial investments) or may not generate monetary savings fast enough to sustain a market for ICSs or modern fuels.

Nonetheless, also in rural areas, higher income households are more prone to switch fuels or to use an ICS $[11,15]$. This is also confirmed in studies of companies trying to commercialize cooking stoves. In a study in India, none of the studied companies were targeting the poorest households, since these households could not afford to buy the stoves and/or the accompanying fuel [16]. Hanna et al. [17] reported that few households are willing to invest in an ICS, even if the stoves are subsidized. This was also reported by Mobarak et al. [18]. ICS projects often chose cheap solutions in order to make the stoves affordable, but these stoves may fail both to improve indoor air quality and to reduce fuel use [17] since the stoves are not of sufficient quality. ICSs come in many shapes and with varying performances; from simple, locally-produced mud stoves, to factory produced rocket stoves and gasifier stoves. In a gasifier stove, the fuel is first gasified in a chamber with an oxygen deficit, creating syngas ( $\mathrm{CO}$ and $\left.\mathrm{H}_{2}\right)$, which, in a second step, is used as a gaseous fuel for cooking. In terms of the decrease of particle emissions damaging to health, the gasifier stove has been shown to be superior to other ICS options in laboratory 
tests [10]. There might thus be a need for programs allowing households to purchase more expensive stoves, which actually make a clear difference.

Many ICS programs have so far had a low rate of success [19]. Shepherd [20] explains the low rate of success of the early programs by the fact that they focused on rural areas, where the stove will not result in monetary savings, but only in time savings. Another explanation for why programs disseminating stoves for free or heavily subsidized fail may be that stove designs have not properly reflected households' cooking needs. In a recent study in India, where stoves were handed out in a randomized experiment, there were some positive effects on indoor air pollution during the first year, but this effect deteriorated quickly because of poor maintenance. The study concluded that the households who spent time and money on stove maintenance actually lost in total welfare, since the low improvements in reduced air pollution and increased efficiencies did not outweigh the cost of maintenance [17]. In another recent study, where stoves, although of higher quality, also were handed out randomly in Senegal, a reduction of $30 \%$ in fuel wood use was observed [21]. There may thus be large impact differences between stove types and between various deployment areas.

At the same time, as large amounts of biomass are combusted inefficiently for residential use with severe health impacts, many nations today aim at increasing their usage of biomass for electricity generation and/or transport biofuel production, both to address the threats of global warming, but also due to an increased interest in national energy security. However, biomass-based electricity generation is generally more expensive than coal-based, partly because of a higher price per unit of energy for biomass compared to coal [22]. Furthermore, worries have been voiced that an increased supply of biomass met through plantations will outcompete food production and, thus, lead to higher food prices, targeting especially poor landless households, e.g., [23].

As a part of the Kyoto Protocol, the Clean Development Mechanism (CDM) has provided the opportunity to support carbon emission reductions in the developing world in order to obtain certified emission reductions (CERs) that can be traded on the carbon market. By design, CDM is a market-based mechanism that should utilize low cost options for the reduction of greenhouse gases (GHG) while at the same time contributing to local sustainability and technology transfer [24]. However, many CDM projects have been criticized for not living up to these expectations. Criticisms include that the projects do little to combat global warming and that they are not contributing to technology transfer and do little for local sustainability, both in terms of benefits for local inhabitants, such as health and income, but also in terms of local environmental improvement [25-27]. Furthermore, many of the projects have been criticized for not being additional [24], meaning that the projects would likely have been carried out also in the absence of CDM support [28]. Although the future of CDM is currently uncertain, a continuation of carbon credit schemes for project funding in the developing world is likely. Special funds for financing of the reduction of short-lived climate gases are currently being established through the Climate and Clean Air Coalition (CCAC) and the World Bank.

Funding of ICSs may be an attractive option, since this is clearly supporting local sustainability and, in light of the limited self-induced dissemination of ICSs [15], could be seen as additional. Current ICS projects are funded though carbon credits based on the assumption that the ICSs reduce deforestation, implying that ICS projects based on carbon credits only are possible in areas with deforestation. However, the compound emitted from inefficient combustion of biomass, which often has the largest impact on the climate, BC, is not included in the Kyoto Protocol [29]. Furthermore, most programs based 
on subsidized ICSs have been met with a low level of success, and there is a risk that these programs undermine business opportunities for local companies trying to achieve a sustainable business model for ICSs. On the other hand, a majority of those that would benefit from an ICS are the rural poor of the developing world who can seldom afford to buy their stove of choice. Bailis et al. [15] warn against solely relying on commercialized ICS dissemination models.

Considering the difficulties ICS programs have faced in the past in rural areas where biomass is collected rather than purchased together with the often hard task of finding alternative occupation, would it instead be possible to regard rural household's biomass collection as work consisting of the gathering of a renewable fuel in the form of collectable biomass; twigs, branches and agricultural residues? The problem is then that the fruit of the labor is an inefficient means of cooking, releasing harmful particles that are the cause of death and disease and, although it can be viewed as a renewable energy source, contributes to global warming through various products of incomplete combustion; e.g., $\mathrm{CH}_{4}$ and $\mathrm{BC}$ [10].

The question that arises is then if it would be possible to create a framework where the rural households perform the same work, but instead would be given a means to obtain an efficient way of cooking, which is less harmful for health, together with monetary compensation for the work, and where a part of the collected biomass is instead used in more energy-efficient conversion devices.

Models for improving rural livelihoods through energy-related business models have been proposed, i.e., [30,31]. Others explore the possibilities of using CDM-funded projects for forest plantations and rural development [32]. Various solutions to reach the bottom of the pyramid, the poorest households, with energy services has been discussed, e.g., [33], though reaching the poorest households is generally problematic, not the least of this being true with regards to ICSs [16].

In this paper, we propose a model partly based on experiences from China [11,34,35], where initial forcing policies in the end resulted in a continuous usage of ICSs, and partly based on the findings that in urban areas in other countries, households have themselves purchased ICS stoves or moved up the fuel ladder, since fuel wood is a traded commodity, and demand-side efficiency measures thus lead to saved costs $[11,15]$. The model proposed in this paper aims to mimic these conditions. The basic principle behind the proposed model is to allow the poor households to either get economic revenues from their collected fuels or to allow them to trade their collected fuels for a more efficient and less polluting fuel, and for money. In this way the problem of disturbing the market by stove subsidies may be sidestepped, and at the same time, monetary incentives for the households to use the fuel more efficiently are created. Further, the model is based on a systems expansion, since the deployment of ICS is addressed by involving an external buyer of the excess fuel wood, and it is this external buyer who is providing the monetary payments to the ICS users. This external buyer is assumed to be a thermal power plant.

The proposed model aims to increase the adoption of ICSs, raise rural living standards and provide a low carbon fuel for electricity generation. However, there are issues arising in response to the proposed model. One such issue is that there is a risk of a higher outtake of fuel wood due to the fuel wood pricing, implying a risk of deforestation. A further issue is whether the compensation to households is sufficient to actually influence households' incentives. A third issue is if the revenues from carbon credits and sales of biomass can cover the logistics cost of the model implementation. Thus, the aim of this article is both to propose and present a conceptual model and to perform a preliminary assessment of an implementation of this model, including qualitative evaluations of the risk of deforestation and 
households' possible responses to the option of selling collected biomass and a quantitative assessment of its financial feasibility. The qualitative evaluations are carried out aided by the literature on ICS programs, rural households' fuel choices and fuel wood collection, and a simplistic model calculation of a possible model implementation is undertaken to determine its financial feasibility.

Section 2 presents the proposed conceptual model together with a possible model implementation. In Section 3, a method for calculation of the economic flows and emission impacts of the model is presented, and Section 4 presents the calculation results of the model implementation. Possible caveats of the model, such as the risk of deforestation and the households' anticipated response, are discussed in Section 5, and finally, in Section 6, conclusions are presented.

\section{The Proposed Model}

The main principle behind the model is to create a price for collected biomass to allow households to trade excess biomass, thus giving them economic incentives for energy efficiency gains. This would initially provide revenues, which could cover costs for stove purchasing and repair, and, in the longer term, an added income. A price for the collected biomass that is higher than the current opportunity cost of fuel wood collection, or the current market price if any, would give stronger incentives for rural households to make efforts for increased stove efficiency.

Households already used to purchase fuels for cooking are more likely to purchase and use an ICS, since a more efficient utilization of the purchased fuel leads to direct monetary savings [11]. In the same way, the provision of an opportunity for the rural population to sell their collected fuel wood would give incentives for more efficient biomass use, since unused fuel wood may instead be sold.

In a review of studies of ICS adoption income, access to credit, the price of fuel wood, social status, education and household size were found to be significant factors in several of the studies [36]. The first three of these factors are of particular interest to the current model, although the paper also found some disparities between modeling approaches, and the factors influencing ICS adoption may be complex and not yet fully understood.

A recent study has also pointed out liquidity constraints as a main barrier [37]. Although many households are often already paying a high opportunity cost for the collected fuel wood, fuel wood savings might not directly lead to sufficient short-term monetary revenues to enable a stove purchase. Further, the person in charge of the household economy may not be involved in fuel gathering and cooking activities and may therefore not sufficiently value the possibilities of time savings [38].

By enforcing a rule stating that only households with an ICS installed are allowed to sell fuel wood at the higher price, sufficient incentives for the households to install an ICS may be created (if the revenues of fuel wood sales results in a short enough payback time). In this way, the model would resemble many aspects of the Chinese program described by Smith et al. [34]. By sustaining a possibility to make money from using less biomass, incentives for maintaining a high fuel efficiency are provided, thereby mimicking the situation in places where biomass is purchased, as in more urban areas, where ICS programs historically have been more successful [11,15]. Furthermore, by providing an income source from trading the biomass, the liquidity barrier is lowered. It should be pointed out that the barriers possibly overcome by the proposed model are by no means the only possible barriers for ICS adoption; see, for example, [39] for a discussion. 
In the proposed model, demand for biomass for electricity, or heat and power, is part of the price creating mechanism. Thus, the model also requires a system and infrastructure for biomass transport from villages to decentralized or centralized power or heat and power plants. A schematic diagram of an application of the proposed model is presented in Figure 1.

Figure 1. Schematic presentation of the proposed model. Red arrows represent collected biomass and green arrows represent monetary flows.

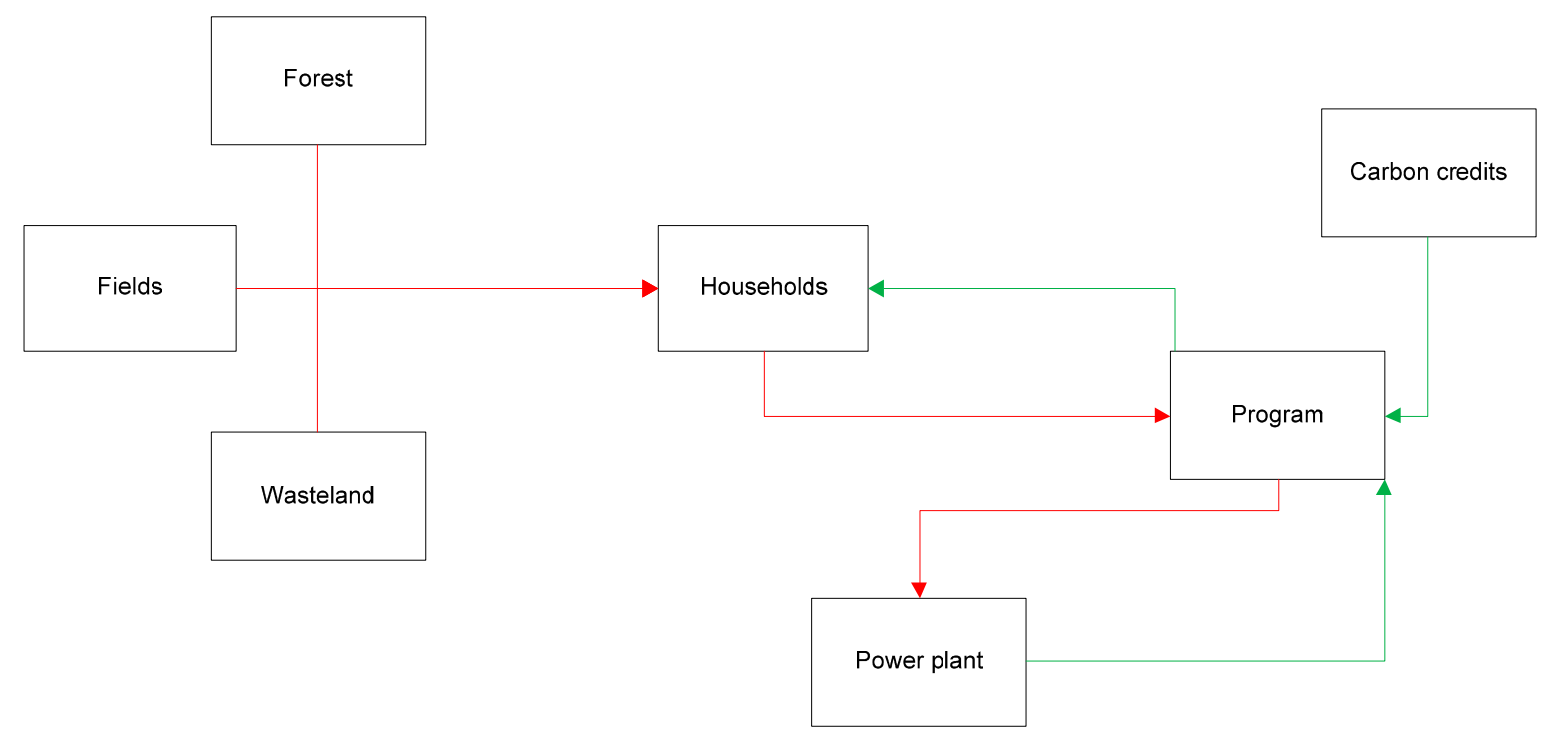

The Program represents a body, which acts as an intermediary between electricity producers, such as a power plant and the households. In a pure market model, such an intermediary body would not be required, but since carbon credits are still mainly dealt with on a program basis, we have included this body here. This body also represents the possibly needed monitoring and may act as a financial intermediary facilitating the purchase of both ICSs and vehicles for biomass transport.

In a simple application of the model, the excess fuel wood, gathered by the households, but not needed by the households for cooking due to the use of ICSs, is collected from households or from a central site in each village by trucks and then transported to a biomass demand facility. This biomass demand facility is assumed to be the abovementioned power plant, or a combined heat and power plant, buying the biomass from the households. The plant may either be a large coal power plant, in which a certain amount of biomass can be co-combusted, thereby reducing coal demand [40], or a smaller biomass power or heat and power plant. In the model application, we assume a system where biomass needs first to be collected at the households, using small trucks, and transported to intermediary storage, where, then, larger trucks perform the transport to the power plant. Should the village structure be denser, collection with a large truck may be sufficient. Although more complex solutions in terms of utilization of the collected biomass would be possible, including distributed generation facilities, intermediate pelletization or torrefaction of biomass, here we consider a simple application of the model design despite that this might not be an optimized design, which would depend on local conditions. In this example, we try to model a logistics system, where houses are separated, but still connected by dirt roads. 
The model would result in demand side (households' biomass cooking) energy efficiency due to the adoption of ICSs and supply-side (electricity generation) carbon intensity reductions when biomass substitutes coal in power generation. Reductions of greenhouse gas emissions (GHGs) would then be achieved due to the ICS adoption, reduced emissions of $\mathrm{CH}_{4}$ and $\mathrm{BC}$ and reduced $\mathrm{CO}_{2}$ emissions related to the fuel substitution in the power generation. Assuming carbon neutral biomass harvests, an issue that will be further discussed later, there are thus two different contributions to GHG emission reductions that both may attract carbon market funds, either through CDM, a future CDM replacement or through alternative markets specializing in short-lived climate warming agents, as the recently established GACC fund [41].

In addition to the critical issues mentioned at the end of the previous section relating to the general concept, there are a few more issues relating to the specific model application presented in the present section. In particular, the successful application of the proposed model suggests the requirement of a certain infrastructural and institutional level, e.g., with regards to road standards and thermal power plant sites located not too far away from the ICS deployment site. Further, the proposed model is better suited for countries with increasing forest resources and possibly also with policies for the use of biomass for electricity generation in place. Thus, countries suitable for the model application are, e.g., China and SE Asian countries, rather than Sub-Saharan African countries.

\section{Emissions and Income Calculations Based on the Model Principles}

\subsection{Calculation Methods}

Here, a simple calculation of revenue streams is outlined in order to address the financial feasibility of the model application example presented in Section 2. The calculations are performed based on units of traded biomass, where traded biomass equals the amount of biomass sold by the households and then transported to the site of the power plant. Revenues are obtained from selling the biomass to the power plant and from selling carbon credits. The costs result from the logistics operation. The result of the calculation, the calculated profit, should be a sufficient compensation for the households for the work carried out and also cover costs for program monitoring.

The total profit, calculated per ton of traded biomass, is given by:

$$
P=R-C_{S T}-C_{L T}+E_{T} * C E R
$$

where $P$ is profit, $R$ is the revenue for the sold biomass, $C_{S T}$ is the cost for collection with small trucks and $C_{L T}$ is the cost for collection with large trucks, $E_{T}$ is the emission reductions in $\mathrm{CO}_{2}$-equivalents $\left(\mathrm{CO}_{2} \mathrm{eq}\right)$ and CER is the price per ton $\mathrm{CO}_{2}$ eq saved.

The cost for collection with trucks per ton of traded biomass is calculated as:

$$
C_{S T}, C_{L T}=\frac{A+M+\left(Y D * F_{C}+Y T * F_{I}\right) * F_{P}+D_{S}}{Y T B}
$$

where $A$ is the annualized investment cost, $M$ is the annual maintenance cost, $Y D$ is the annually driven distance, $F_{C}$ is the fuel consumption per driven distance, $Y T$ is the time annually that the engine is assumed to run idle and $F_{I}$ is the assumed fuel consumption while idling per time unit, $F_{P}$ is fuel price, 
$D_{S}$ is the annual salary for the driver and $Y T B$ is the total mass of annually transported biomass. The $Y T B$ for small trucks is based on the number of households the truck can visit and how much wood that is collected each time, while the $Y T B$ for large trucks is based on one fully-loaded truck per working day constrained by the maximum load volume and weight. $Y T$ and $F_{I}$ are assumed to only apply to the collection with small trucks, which involves many stops and where the motor might not always be turned off during loading.

The reduction of greenhouse agents per ton of traded biomass, $\mathrm{E}_{\mathrm{T}}$, is given by:

$$
E_{T}=E_{B}-\frac{E_{I C S}}{R_{F}}-E_{S T}-E_{\mathrm{LT}}+E_{E C}
$$

where $E_{B}$ is the emissions per ton of biomass from traditional cooking, $E_{I C S}$ is the emissions from cooking with the ICS per ton of biomass, $R_{F}$ represents the efficiency gain (expressed as the quotient when dividing the efficiency of the ICS with that of traditional cooking) due to the ICS introduction, $E_{S T}$ and $E_{L T}$ are the emissions from trucks calculated per amount of fuel used yearly divided by $Y T B$ and $E_{E C}$ is the emission reduction due to decreased coal use at the power plant (per transported ton of biomass). All emissions are presented and calculated in $\mathrm{CO}_{2} \mathrm{eq}$, hence assumptions on how to recalculate $\mathrm{BC}$ to $\mathrm{CO}_{2}$ eq are needed. Finally, a brief sensitivity analysis is carried out testing the sensitivity to different assumptions and to different CER levels.

\subsection{Assumptions}

Since the conceptual model and the application of the model are not based on any real cases, assumptions are required to calculate the revenue streams. The key assumptions are presented below and in Table 1. After the presentation of each of the key assumptions, the sensitivity tests carried out are presented.

The price that the power plant would be paying for the purchased biomass is based on the coal price, currently 2-3€/GJ (World Energy Outlook 2013 (Price was originally given in USD. A 2013 mean value has been used for conversion: $1 €=0.75 \$)$ ); however, a conservative assumption is made, and it is assumed that the biomass can be sold at a price of only $1 €$ per GJ (15€ per ton of biomass), which is in the lower range of estimated present and future costs for global biomass production from energy crops [22]. The sensitivity of these assumptions is tested when the price is doubled to $2 € / \mathrm{GJ}$.

We assume that a large truck can visit one village each day and load up fully and that the one-way distance from the village to the final destination is $100 \mathrm{~km}$. The need for collection with smaller trucks is based on an assumed setting with separated households, while a more clustered village structure would allow for direct collection with large trucks. In addition to their $\mathrm{CO}_{2}$ emissions, the trucks carrying the biomass from the villages are also emitting BC. We use the median value found for trucks in China [42], although newer trucks have lower emissions. In our base case, we are assuming that households are visited once per week and that the small trucks can visit six households per hour. This assumption is, however, tested, and the impact on the results of a slow collection rate of only three households per hour and the case of a dense village where no small trucks are needed at all are investigated. 
Table 1. Assumptions for calculations.

\begin{tabular}{lll}
\hline \multirow{3}{*}{ Fuel Wood } & Household daily wood consumption & Mean: $10 \mathrm{~kg}$ \\
& Price when sold to energy company & $1 € / \mathrm{GJ}$ \\
& Density of piled wood & $0.3 \mathrm{ton} / \mathrm{m}^{3}$ \\
\hline Diesel Cost & & $1 € / \mathrm{L}$ \\
\hline \multirow{2}{*}{ Drivers } & Annual salary & $2000 €$ \\
& Work hours & $160 \mathrm{~h} / \mathrm{month}$ \\
\hline \multirow{5}{*}{ Small Truck } & Annualized investment cost & $2000 € /$ Year \\
& Maintenance cost & $2000 € /$ year \\
& Load & 1.8 ton \\
& Fuel consumption & $0.2 \mathrm{~L} / \mathrm{km}$ \\
& Truck idling & $1.5 \mathrm{~L} / \mathrm{h}[43]$ \\
& Household visits & $3-6 / \mathrm{h}$ \\
& Average distance between households & $200 \mathrm{~m}$ \\
\hline & Annualized investment cost & $10,000 € /$ Year \\
& Maintenance cost & $10,000 € /$ Year \\
& Load weight & $30 \mathrm{ton}$ \\
Large truck & Load volume & $100 \mathrm{~m}$ \\
& Fuel consumption & $0.6 \mathrm{~L} / \mathrm{km}$ \\
& Villages visited & $1 / \mathrm{day}$ \\
& Average distance between villages and power plant & $100 \mathrm{~km}$ \\
\hline
\end{tabular}

In the calculations, we assume that a modified coal power plant uses the biomass through co-firing. Utilization of up to $10 \%-15 \%$ of wood (on a heating value basis) does not decrease the conversion efficiency more than $1.5 \%$ [40]. The practice of co-firing currently exists, mainly in Europe [40]. The investment costs for modifying a coal power plant to be able to handle co-firing (40-225€/kW biomass capacity (values are for direct co-firing and low levels of biomass)) [44] calculated per ton of biomass (over the plant lifetime) is comparable with the other costs in Equation and this extra cost is also taken into account when assuming a very low price for the biomass sold to the power plant.

The future of the CDM mechanism (and other carbon markets) is uncertain, and so is the price for future CERs. However, the transfer of funds from developed to developing countries for carbon mitigation in a post-Kyoto CDM or a similar mechanism is likely also in future climate policy agreements, and the existence of such a mechanism in the future is thus assumed. Mechanisms for funding of the reduction of $\mathrm{BC}$ emissions are more uncertain, since they do not exist today. However, $\mathrm{BC}$ mitigation has gained increased attention, and there are recent initiatives aimed towards this goal [45].

The price of CERs has decreased from above 20€/ton $\mathrm{CO}_{2}$ eq in mid-2008 [46] to around only $1 € /$ ton $\mathrm{CO}_{2}$ eq in October, 2012 [47]. Here, we use CER prices within this range with a base CER assumption of $10 €$ per ton $\mathrm{CO}_{2} \mathrm{eq}$, and as a sensitivity analysis we vary the CER price between 0 and $20 € /$ ton $\mathrm{CO}_{2}$ eq. CERs are assumed to be obtainable both from GHGs included in the Kyoto Protocol and for $\mathrm{BC}$ emissions. We assume the same level of funding based on $\mathrm{CO}_{2}$-equivalents using the $\mathrm{GWP}_{100}$ (Global Warming Potential for 100 year interval) scale for the BC emission. The highest CER price assumed $\left(20 € /\right.$ ton $\left.\mathrm{CO}_{2} \mathrm{eq}\right)$ is still well below future cost estimates for carbon capture and storage and other mitigation options; see e.g., [48,49]. 
There are a number of ICS designs. Based on the limited success of previous programs with low quality stoves, where, often, price has been chosen over quality [17], and given that one of the aims of the proposed model is to facilitate households to be able to afford more efficient and convenient stove types having the potential to make a significant difference, our assumption for the calculations is a modern gasifier ICS. This is the only design that reduces particle emissions to levels approaching those of an LPG stove [10]. However, the revenue assumed from selling CERs based on reduced emissions from households' cooking is uncertain due to two reasons. Firstly, the usage of the ICSs in households may differ substantially from lab setups, making actual reduction uncertain at present. Furthermore, any compensation for such reductions is uncertain, due to the fact that no such framework for $\mathrm{BC}$ emissions is currently in place. In order to take the larger uncertainty with regards to BC credits into account, calculations without any CER due to emission reductions within the households (due to ICS adoption) are carried out.

The households' consumption of biomass for cooking per day is assumed to decrease from $10 \mathrm{~kg}$ to $5 \mathrm{~kg}$ with the ICS adoption. We further assume that the Program has established a quota on the amount the households are allowed to trade to the program to $10 \mathrm{~kg}$ a day and that the households actually also trade this amount. This assumption is tested in the sensitivity analysis when we assume that households only trade the amount of biomass saved due to the ICS adoption, i.e., they do not increase their gathering. This may be either due to a restricted quota or due to the households being unable or unwilling to increase their gathering.

We are assuming an efficiency improvement factor of two as a consequence of the ICS adoption (see Table 2). This value is however based on laboratory measurements and may not be reached in real-life applications. Therefore, a reduction of the efficiency improvement factor to 1.5 and the emission level to 0.815 (the average of values for traditional cooking and the ICS in the laboratory results) is tested in a sensitivity calculation. Finally, the assumption of the density of piled wood is reduced to 0.15 ton per $\mathrm{m}^{3}$ (half the value given in Table 1 ).

Table 2. Global Warming Potential (GWP)-emissions of the Improved Cooking Stove (ICS) compared to a traditional tripod (calculated from values compiled by Grieshop et al. [10]).

\begin{tabular}{ccc}
\hline kgCO$_{2}$ eq per kg Fuel & Efficiency Improvement Factor \\
\hline Tripod & $1.45^{1}$ & 1 \\
ICS (gasifier stove) & $0.18^{1}$ & 2 \\
\hline
\end{tabular}

${ }^{1}$ Gathered biomass is assumed to be carbon neutral. All emitted black carbon (BC) is assumed to reach the atmosphere. Included emissions are $\mathrm{CO}$ and $\mathrm{CH}_{4}$, (included in the Kyoto Protocol) and $\mathrm{BC}$, organic carbon (negative) and NMHCs (Non-methane hydrocarbons) (not included in the Kyoto Protocol). The total emissions (in $\mathrm{kgCO}_{2}$ eq per $\mathrm{kg}$ ) are calculated as the sum of the different emitted compounds given as $\mathrm{gC} \mathrm{per} \mathrm{kg}$ from [10] as $\frac{k g \mathrm{gO}_{2} e q}{k g_{\text {fuel }}}=\sum_{i} G W P_{i} *\left(\frac{k g w}{k g C}\right)_{i} *\left(\frac{k g C}{k g_{f u e l}}\right)_{i}$, where $G W P_{i}$ is the GWP value for emission $\mathrm{i},\left(\frac{w}{C}\right)_{i}$ is the total molecular weight related to the weight of carbon atoms in the molecule and $\left(\frac{\mathrm{kgC}}{\mathrm{kg}_{\text {fuel }}}\right)_{i}$ is the $\mathrm{kg}$ of $\mathrm{C}$ carbon ending up in emission i. GWP values for BC and organic carbon are assumed as 455 and $-35 \mathrm{GWP}_{100}$, respectively [50], in the lower range of current estimations. 


\section{Results of Cost Calculations}

\subsection{Emissions}

As discussed above, the model would lead to reductions of $\mathrm{CO}_{2} \mathrm{eq}$ emissions in two instances, both due to the improved combustion efficiency in households' cooking and due to displacement of coal in electricity generation. The resulting emission reductions per amount of traded biomass for the different posts are presented in Table 3.

Table 3. Emissions reductions ( $\mathrm{kg} \mathrm{CO} 2 \mathrm{eq})$ per amount of traded biomass $(\mathrm{kg})$.

\begin{tabular}{cc}
\hline ICS & $1.36^{*}$ \\
Displaced coal & $1.65^{* *}$ \\
Small truck & -0.022 \\
Large truck & -0.012 \\
\hline
\end{tabular}

* Assuming that households sell an amount equal to what they used each day before the program (10 kg/day);

** Assuming $15 \mathrm{GJ} /$ ton biomass and $30 \mathrm{GJ} /$ ton coal (each ton of biomass displaces 0.5 ton of coal). The carbon content of coal is assumed to be 0.9 .

\subsection{Profit}

The results of the profit calculation, Equation (1), are presented in Table 4 and Figure 2. The middle column $(\mathrm{CER}=10)$, top row, of Table 4 corresponds to Figure 2. For further details regarding the results (base assumptions) of the assumed costs for different aspects of the collection with trucks, see Figure 3. The results are presented for various parameter assumptions, as discussed in Section 3. The calculations show a positive economic result for most assumptions at CER levels of 10 and $20 € /$ ton $\mathrm{CO}_{2}$-equivalents. When the value of carbon credits is zero, the results become slightly negative for most assumptions. In the next section, we discuss whether or not these results are sufficient for both the acquirement of an ICS and for compensation for the work carried out. One result that might need some explanation is the increase of profit per traded biomass when households are assumed to sell only $5 \mathrm{~kg}$ /day. This is because the amount of the revenue from reduced emissions due to the ICS adoption is distributed over a reduced amount of traded biomass.

Table 4. Profit, $P$, in€/ton traded biomass, for different assumptions of truck collections rates and CER prices. Six households $(\mathrm{HH})$ per hour is the assumed small truck collection rate for all but the second and third rows.

\begin{tabular}{cccc}
\hline Cases & CER $=\mathbf{0}$ & CER $=\mathbf{1 0}$ & CER $=\mathbf{2 0}$ \\
\hline Small truck collection rate: $6 \mathrm{HH} / \mathrm{h}$ & -3 & 26 & 56 \\
2€/GJ biomass & 12 & 41 & 71 \\
Small truck collection rate: $3 \mathrm{HH} / \mathrm{h}$ & -14 & 15 & 45 \\
No small truck (cluster village structure) & 8 & 38 & 68 \\
No CERS from ICS emission reductions & -3 & 13 & 29 \\
Households trade 5 kg/day & -15 & 28 & 72 \\
Lower stove performance & -3 & 22 & 47 \\
Wood density halved & -10 & 20 & 49 \\
\hline
\end{tabular}


Figure 2. Costs, revenues and total profit of the presented model application under base assumption displayed for the individual posts.

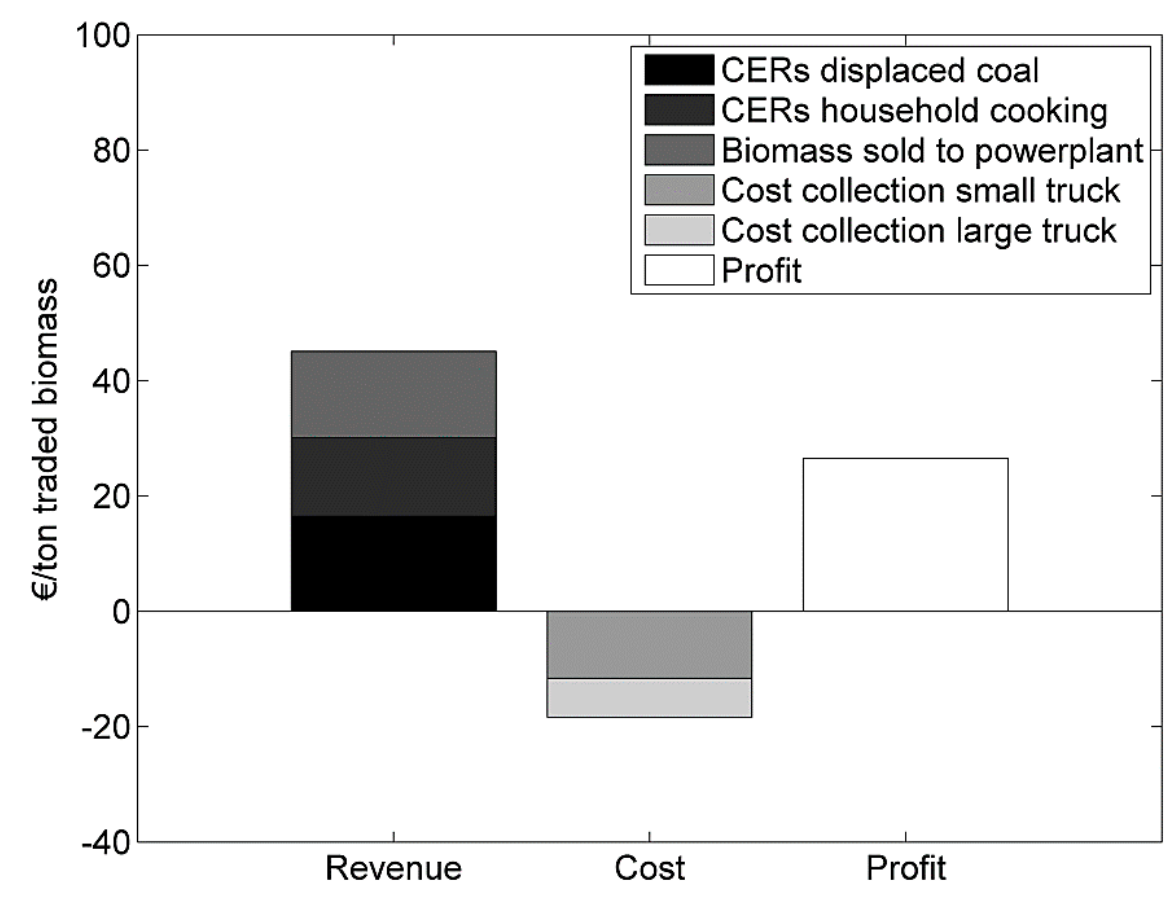

Figure 3. Base case results for the costs of the collection with the small and large trucks.

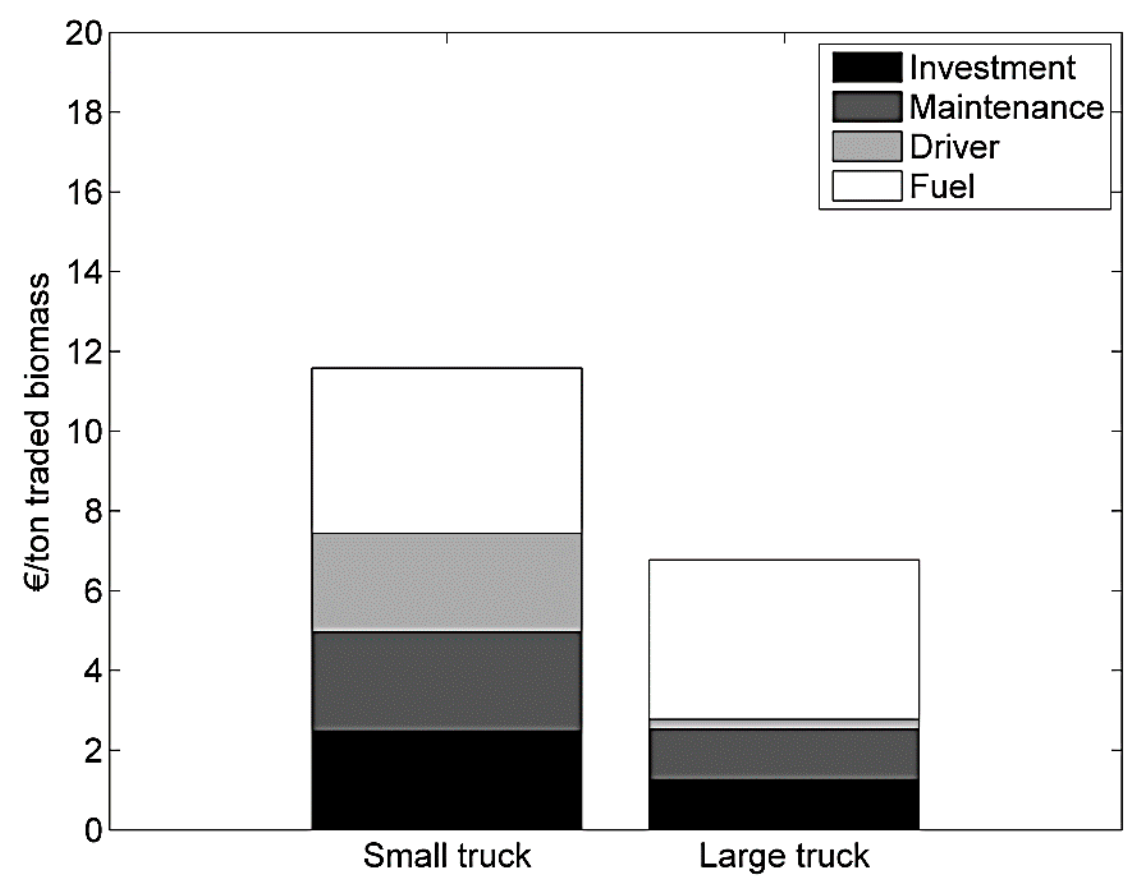

It should also be stressed that the presented profit calculations are simplified and does not reflect the full complexity concerning household costs and benefits, which often depend on stove type, cooking and social practices and may vary both between households and areas; see [51] for an exploration of the set of parameters affecting the costs and benefits of ICS adoption. 


\section{Discussion}

\subsection{Compensation to Households}

The profit, $\mathrm{P}$ in Equation 1, needs to be sufficiently large, not only to provide reasonable additional economic compensation to the households, but also to cover any needed monitoring and Program overhead. Therefore, we need to calculate the gatherers' potential profit from the traded biomass and compare this with available values of monetary compensations in rural areas. In order to make such a calculation, the fuel wood gathering rate is required. Amacher et al. [52] provides estimates for fuel wood gathering rates in different areas in Nepal; $7 \mathrm{~kg}$ of wood per hour in the Terai and $33 \mathrm{~kg}$ per hour in the hills, indicating large differences between areas. Since the proposed model is mainly aimed at areas without biomass shortages, a fuel wood collection rate of $10 \mathrm{~kg} / \mathrm{h}$ is assumed.

Minimum monthly wages in the textile industries in South and South East Asia vary from about $50 €$ per month in India and Bangladesh, $73 €$ in Cambodia, $82 €$ in Indonesia to 175 and $196 €$ in China and Malaysia, respectively, based on $48 \mathrm{~h}$ work weeks [53]. This translates to hourly wages from $0.25 €$ (Bangladesh) to $0.95 €$ (Malaysia). Hence, the proposed model, under the assumptions outlined in Section 3, may be able to provide attractive compensation in some of these countries.

The above assumed $10 \mathrm{~kg} / \mathrm{h}$ collection rate then requires a compensation at $25 € /$ ton traded biomass to reach the minimum wages in India and Bangladesh. This level appears to be obtainable for several of the parameter assumptions if climate funding based on CERs is obtained and is close to the results for the base case assumptions, see Table 4.

As will be further discussed in Section 5.3, one possible candidate country for applications of the proposed model is Vietnam. Vietnam has undergone a forest transition; there is a comparatively high infrastructure level, a high dependence on coal for electricity generation, while a majority of rural households still depend on fuel wood for cooking. During the rural electrification program in Vietnam, a rural survey was undertaken to measure the benefits from electrification, as well as various household characteristics [54]. The median annual cash income for the whole survey was approximately $1000 €$ per household (Income originally recorded in VND. A 2013 mean value was used for conversion $1 €=27,000$ VND.). In some of the poorer communes, the median household income was only around about $200 €$ [55]. Participation in the proposed program and $10 \mathrm{~kg}$ of sold biomass daily at a price of $25 €$ per ton would translate to around $90 €$ on a yearly basis. Hence, participation could increase the household cash income substantially. Furthermore, the commune averages of fuel wood gathering rate ranged from 3 to $18 \mathrm{~kg} / \mathrm{h}$ (mean and median of $9 \mathrm{~kg} / \mathrm{h}$ ) [55], which would give an hourly income from 0.075 to $0.45 € / \mathrm{h}$, assuming $25 € /$ ton of traded biomass.

Minimum monthly wages for civil servants and state employees in Vietnam are approximately $41 €$ (in 2014) [56], which translates to about $0.24 € / \mathrm{h}$ (for a $40 \mathrm{~h}$ work week).

An assumption of a price of $50 €$ per stove together with the assumption of $10 \mathrm{~kg}$ of sold biomass a day and a monetary compensation of $25 €$ per ton leads to a payback time of about 6-7 months; i.e., the stove price divided by the monthly extra income. Barnes et al. [11] estimated that rural households may require payback times as short as $2-3$ months in order to be able to make the investments. Thus, even if the monetary compensation can be considered comparable to other income sources currently available to the households, it may still be hard for many households to make the initial investment. It may 
therefore be necessary to couple household participation with favorable loans that can be amortized through fuel wood collection.

A recent study has found both that liquidity constraints are indeed a barrier for stove adoption and that when households were offered either time payments or a free trial of charcoal ICSs, uptake increased from $5 \%$ to $25 \%$. When households were also offered to be able to withdraw at any time without making any further payments, the uptake increased to $45 \%$ [57]. While these stoves were aimed at charcoal, an already commercial fuel, this shows that liquidity constraints may indeed be an important barrier.

Above, we have assumed a 50\% efficiency improvement due to the adoption of a modern gasifier ICS. Two recent studies of randomly distributed ICSs have resulted in considerably lower, and somewhat different, conclusions regarding the efficiency improvements of ICSs. Hanna et al. [17] found that the ICSs distributed in their study do not reduce the need for fuel wood and only slightly improved the indoor air quality during the first year. A possible explanation for these results may be that the stoves were not of sufficient quality and not suited enough to the households' cooking practices. Benschand Peters [21], on the other hand, found a reduction of $30 \%$ in fuel wood use.

Households in the developing world are often constrained by a poor household economy, making short payback times essential. It is, therefore, possible that households, even with the extra income from selling fuel wood, would choose a cheap stove that would not improve their cooking situation. There may thus be a need for stove quality regulation, and since the discussed model may provide a significant income improvement, it would be possible also to enforce policies regarding the ICS quality and performance, although these stoves may carry higher initial expenses. The Chinese program continued to monitor stove quality [15], while another initially successful stove program, the Kenyan Jiko program, discontinued monitoring of stove quality [15], which led to a decline in stove quality, even though incentives for efficient stoves were in place. This implies a need for stove manufacturers to comply with demands on stove quality with regards to efficiency and emission levels.

\subsection{Assumptions of Future Co-Firing}

In the program calculation an assumption of the existence of a not too distant coal-power plant with co-firing capabilities is made. Co-firing is considered as one the of the most cost-effective ways to reduce $\mathrm{CO}_{2}$ emissions in the short term [58] and can even be profitable if biomass is obtainable at sufficiently low prices. There is however an investment to overcome which, although this cost is low compared to other technologies, requires a secure supply of low cost biomass to reach profitability. However, biomass is generally more expensive than coal on an energy basis. In the program calculations, assumptions of prices below the current coal prices are made for the biomass price to accommodate for this. Currently the spread of co-firing in the developing world is low but existing in China [59] and India [60]. After retrofitting, a co-fired power plant is flexible in the sense that it can vary the amount of biomass up to the installed (biomass) capacity, and thus adjust according to the current fuel prices.

\subsection{Suitable Locations, Deforestation and Landless Households}

As mentioned above, an application of the proposed model may, besides creating increased incentives for stove adoption, also raise incentives for deforestation. In order to avoid a too high outtake of biomass, a possible solution would be to enforce a quota limiting the amount of biomass households are allowed 
to sell during a given period of time. Enforcement of a quota may require identification of the households, for example through mobile technology capable of recognizing registered fingerprints. A quota may however decrease household incentives for purchasing and using an ICS more efficiently. The theoretic framework used in studies of household fuel wood collection $[52,61,62]$ can aid in this discussion. The cost of collected fuel wood can be considered to be a function of the time required to collect a certain amount of fuel wood and the opportunity cost of time. The households' supply of labor limits fuel wood collection [63]. Since time is limited, each additional increment of time spent on fuel collection becomes more expensive, and thus, even if assuming a constant return on spent time, the cost per unit fuel wood will increase due to an increased cost of time. Since the returns on fuel wood collection time are likely to diminish, households' will collect from the most easily gathered fuel sources first (likely close to the household). Several studies have pointed towards the sensitivity of households in response to differences in opportunity cost for various sources of fuel wood collection $[62,64]$.

The enforcement of a limit on how much biomass households are allowed to trade for money may have negative effects for the premises of the model, since if biomass is in abundance, i.e., too easily gathered, the household may not gain the incentives for using the fuel more efficiently. However, the assumption of diminishing returns on time spent collecting biomass together with an increased opportunity cost for the time itself, for each additional unit of time, leads to at least a small increment in incentives for using the biomass more efficiently. The proper quota and price to balance incentives and environmental considerations are likely to vary between different areas and have to be determined by empirical studies.

Although the links between households' fuel wood collection and deforestation are still unclear [65], deforestation as a consequence of more commercial operations, such as charcoal production, have been observed [66]. It has been argued that as long as it is the value of the forest itself that is driving the deforestation, the deforestation is balanced by forestry, because when scarcity increases the price of forest products, investments in forestry and plantations becomes more profitable [67]. Empirical examples of this have been noted in India, where forest cover increased with a higher price on wood products [68]. This has also been noted on the household level, when households increased the production of fuel wood for personal use in response to forests degradation [52,69]. However, this type of scarcity-induced reforestation only ensures that the market-based values are preserved; it does not guarantee control over erosion, biodiversity, genetic reserves and global climate change [67]. It is, therefore, vital that at least until the full consequences of the proposed model have been empirically determined, any such attempt takes place within areas where biomass is currently harvested sustainably.

It should be noted also that in areas experiencing fuel shortages, for example due to deforestation, traditional ICS programs may experience success, given that stoves are of sufficient quality [21]. The model suggested in the present paper should hence be aimed at areas where poor households have a high dependency on collected biomass fuel, but where deforestation is currently not immediate. Several developing countries have undergone, or are undergoing, a forest transition; the process in which deforestation has been halted and turned and where, instead, reforestation is currently taking place. Rudel et al. [70] describes two distinct possible paths for this forest transition: (1) industrialization draws people from the countryside, and together with the intensification of agriculture, this leaves land unused where forest can regrow; (2) scarcity-induced reforestation; initial deforestation increases the price on wood products, which leads to intensified forestry. As noted, scarcity-induced reforestation may not 
provide natural forests and may not preserve biological values; however, the increased possible outtakes from this intensified forestry can make extraction from natural forests less profitable, which, in turn, may benefit from this process. Several countries in Asia have already been documented to have experienced a forest transition, while at the same time, many rural households are dependent on collected fuel wood. These include Bhutan, China, India, Philippines and Vietnam, and in Thailand and the Malaysian Peninsula, the forest cover has been stable for over 20 years, however without any reforestation [71].

Tree planting as a response to forest degradation and an increased fuel wood price is mainly possible on private land. Therefore, in societies where fuel wood collection is mainly carried out on private lands, poor landless households may not be able to participate and may face an increased fuel wood price as a consequence of an application of the proposed model. To some extent, the quota on the amount of wood allowed to be sold at the higher price may result in a higher level of inclusion, since households being unable to collect enough to fill their quota (for various reasons) may act as both buyers and sellers of fuel wood. Households may not be able to collect because of a shortage of labor supply [63] or because they are landless and the fuel collection in the area mainly occurs on private land. Those who collect and wish to sell more than their quota must then engage the households that are not collecting and, thus, divert money and, thus, incentives for using the ICS also to these households. However, how the exact consequences of this is an empirical question. The risk of excluding poor landless households should be considered for any application of the proposed model where this may be relevant. Areas where all households either own their own land or have access to commons where deforestation of pristine forests is not immediate are therefore suitable for applications of the model.

The relatively high complexity of the model provides some infrastructural and institutional constraints on suitable areas, including the existence of roads, power plants and electricity distribution systems. As mentioned, an institutional body is also likely required to deal with carbon credits, administration and monitoring. These constraints limit the number of possible areas, but also seem to overlap with countries undergoing a forest transition and also with countries that have developed rapidly during the last few decades, e.g., China and Vietnam, and with a large rural population still dependent on collected fuel wood. However, economic development need not necessarily lead to a forest transition [71]. In this section, it was shown that there are a number of countries with conditions supporting the proposed model. However, it should also be stressed that implemented in the wrong areas the model may lead to severe negative consequences, i.e. using CDM funding to sponsor deforestation and making it harder for poor landless household to obtain energy for meal preparation.

\section{Conclusions}

The low rate of success experienced by many ICS programs calls for new approaches to stimulate ICS adoption. The basis of the proposed model is an expansion of the system used to address ICS adoption within. By a simple systems expansion, and the combination of energy efficiency through ICS adoption, revenues from sold excess biomass and the use of excess biomass in larger power plants, a local biomass market would be created, leading to economic incentives for household energy efficiency. The revenues households would get from biomass sales would contribute towards enabling households' ICS purchases. The local market interactions of such a model with its market feedback are unlikely in programs handing out or subsidizing pre-designed stoves. The merit of this policy would thus be an 
increased stove uptake and continued usage, leading to multidimensional sustainability, including health, social, local environmental and global climate benefits.

The income calculations based on the model principles show that under many assumptions, the model will lead to a positive result, required to cover the compensation for the work of gathering fuel wood. The calculations also show that revenues from generated carbon credits are essential and that credits from $\mathrm{BC}$ emission reductions would play an important role, but also that the model is financeable through carbon credits within the historic price interval of certified emission reductions (CERs).

We have drawn on previous literature on fuel switching, ICS adoption and fuel wood collection to further discuss some of the model implications. The conclusion from this exercise is that the proposed model principles could increase ICS adoption without leading to deforestation. However, this remains an empirical question. There are also further questions concerning the exact implementation of the model, e.g., how to handle the monetary flows to the household in a safe way, the quota enforcement and risks of corruption. The proposed model is thus only a first conceptual step towards a combined market/policy model, and further research concerning drivers and barriers is required.

\section{Acknowledgments}

This study has contributed from funding by the European Commission to the POEM (Policy options to engage Asian emerging economies in a post-Kyoto regime) project, Grant 226282, and from funding by the Foundation in memory of J. Gust. Richert. Madelene Ostwald is acknowledged for valuable comments on a previous article version.

\section{Author Contributions}

Niklas Vahlne proposed and carried out the study. Erik O. Ahlgren supervised the research. Both authors contributed to preparing and approving the manuscript.

\section{Conflicts of Interest}

The authors declare no conflict of interest.

\section{References}

1. Foell, W.; Pachauri, S.; Spreng, D.; Zerriffi, H. Household cooking fuels and technologies in developing economies. Energ. Policy 2011, 39, 7487-7496.

2. Bruce, N.; Perez-Padilla, R.; Albalak, R. Indoor air pollution in developing countries: A major environmental and public health challenge. Bull. World Health Organ. 2000, 78, 1078-1092.

3. Torres-Duque, C.; Maldonado, D.; Perez-Padilla, R.; Ezzati, M.; Viegi, G. On behalf of the Forum of International Respiratory Societies Task Force on Health Effects of Biomass Exposure, Biomass Fuels and Respiratory Diseases: A Review of the Evidence. Proc. Am. Thorac. Soc. 2008, 5, 577-590.

4. Bond, T.C.; Zarzycki, C.; Flanner, M.G.; Koch, D.M. Quantifying immediate radiative forcing by black carbon and organic matter with the Specific Forcing Pulse. Atmos. Chem. Phys. 2011, 11, 1505-1525. 
5. Bond, T.C.; Sun, H. Can Reducing Black Carbon Emissions Counteract Global Warming? Environ. Sci. Technol. 2005, 39, 5921-5926.

6. Ramanathan, V.; Carmichael, G. Global and regional climate changes due to black carbon. Nat. Geosci. 2008, 1, 221-227.

7. Hansen, J.; Sato, M.; Kharecha, P.; Russell, G.; Lea, D.W.; Siddall, M. Climate change and trace gases. Philos. Trans. R. Soc. A 2007, 365, 1925-1954.

8. Bond, T.; Doherty, S.; Fahey, D.; Forster, P.; Berntsen, T.; DeAngelo, B.; Flanner, M.; Ghan, S.; Kärcher, B.; Koch, D. Bounding the role of black carbon in the climate system: A scientific assessment. J. Geophys. Res. Atmos. 2013, 118, 5380-5552.

9. IEA Statistics \& Balances (2009). Available online: http://www.iea.org (accessed on 21 November 2012).

10. Grieshop, A.P.; Marshall, J.D.; Kandlikar, M. Health and climate benefits of cookstove replacement options. Energ. Policy 2011, 39, 7530-7542.

11. Barnes, D.F.; Openshaw, K.; Smith, K.R.; van der Plas, R. What Makes People Cook with Improved Biomass Stoves? A Comparative International Review of Stove Programs; World Bank Technical Paper No. 242; World Bank: Washington, DC, USA, 1994.

12. Heltberg, R. Fuel switching: Evidence from eight developing countries. Energ. Econ. 2004, 26, 869-887.

13. Gundimeda, H.; Köhlin, G. Fuel demand elasticities for energy and environmental policies: Indian sample survey evidence. Energ. Econ. 2008, 30, 517-546.

14. World Bank. Household Cookstoves, Environment, Health and Climate Change: A New Look at an Old Problem; World Bank: Washington, DC, USA, 2011.

15. Bailis, R.; Cowan, A.; Berrueta, V.; Masera, O. Arresting the Killer in the Kitchen: The Promises and Pitfalls of Commercializing Improved Cookstoves. World Dev. 2009, 37, 1694-1705.

16. Shrimali, G.; Slaski, X.; Thurber, M.C.; Zerriffi, H., Improved stoves in India: A study of sustainable business models. Energ. Policy 2011, 39, 7543-7556.

17. Hanna, R.; Duflo, E.; Greenstone, M. Up in Smoke: The Influence of Household Behavior on the Long-Run Impact of Improved Cooking Stoves; National Bureau of Economic Research: Cambridge, MA, USA, 2012.

18. Mobarak, A.M.; Dwivedi, P.; Bailis, R.; Hildemann, L.; Miller, G. Low demand for nontraditional cookstove technologies. Proc. Natl. Acad. Sci. USA 2012, 109, 10815-10820.

19. Köhlin, G.; Sills, E.O.; Pattanayak, S.K.; Wilfong, C. Energy, Gender and Development: What are the Linkages? Where is the Evidence? World Bank Policy Research Working Paper 5800; World Bank: Washington, DC, USA, 2011.

20. Shepherd, G. Forestry, social forestry, fuelwood and the environment: A tour of the horizon. In Rural Development Forestry Network paper 11a; Overseas Development Institute: London, UK, 1990.

21. Bensch, G.; Peters, J. A Recipe for Success? Randomized Free Distribution of Improved Cooking Stoves in Senegal (1 March 2012) SSRN. Available online: http://ssrn.com/abstract=2030746 (accessed on 21 November 2012).

22. Hoogwijk, M.; Faaij, A.; de Vries, B.; Turkenburg, W. Exploration of regional and global cost - supply curves of biomass energy from short-rotation crops at abandoned cropland and rest land under four IPCC SRES land-use scenarios. Biomass BioEnerg. 2009, 33, 26-43. 
23. Azar, C. Biomass for energy: A dream come true... or a nightmare? Wiley Interdiscip. Revi. Clim. Chang. 2011, 2, 309-323.

24. Paulsson, E. A review of the CDM literature: From fine-tuning to critical scrutiny? Int. Environ. Agreem. Polit. Law Econ. 2009, 9, 63-80.

25. Sterk, W.; Wittneben, B. Enhancing the clean development mechanism through sectoral approaches: Definitions, applications and ways forward. Int. Environ. Agreement Polit. Law Econ. 2006, 6, 271-287.

26. Pearsson, B. Market failure: Why the Clean Development Mechanism won't promote clean development. J. Clean. Prod. 2006, 15, 247-252.

27. Wara, M. Measuring the Clean Development Mechanism's Performance and Potential. UCLA L. Rev. 2008, 55, 1759-1803.

28. Sugiyama, T.; Michaelowa, A. Reconciling the design of CDM with inborn paradox of additionality concept. Clim. Policy 2001, 1, 75-83.

29. Kyoto protocol to the United Nations framework convention on climate change. Available online: unfccc.int/kyoto_protocol/items/2830.php (accessed on 20 November 2014).

30. Biswas, W.K.; Bryce, P.; Diesendorf, M. Model for empowering rural poor through renewable energy technologies in Bangladesh. Environ. Sci. Policy 2001, 4, 333-344.

31. Schillebeeckx, S.J.D.; Parikh, P.; Bansal, R.; George, G. An integrated framework for rural electrification: Adopting a user-centric approach to business model development. Energ. Policy 2012, 48, 687-697.

32. Palm, M.; Ostwald, M.; Berndes, G.; Ravindranath, N.H. Application of Clean Development Mechanism to forest plantation projects and rural development in India. Appl. Geogr. 2009, 29, 2-11.

33. Zerriffi, H. Innovative business models for the scale-up of energy access efforts for the poorest. Curr. Opin. Environ. Sustain. 2011, 3, 272-278.

34. Smith, K.R.; Shuhua, G.; Kun, H.; Daxiong, Q. One hundred million improved cookstoves in China: How was it done? World Dev. 1993, 21, 941-961.

35. Sinton, J.E.; Smith, K.R.; Peabody, J.W.; Yaping, L.; Xiliang, Z.; Edwards, R.; Quan, G. An assessment of programs to promote improved household stoves in China. Energ. Sustain. Dev. 2004, 8, 33-52.

36. Lewis, J.J.; Pattanayak, S.K. Who adopts improved fuels and cookstoves? A systematic review. Environ. Health Perspect. 2012, 120, 637-645.

37. Beltramo, T.; Levine, D.I.; Blalock, G. The Effect of Marketing Messages, Liquidity Constraints, and Household Bargaining on Willingness to Pay for a Nontraditional Cookstove; Working paper series No. WPS-035; Center for Effective Global Action: Berkeley, CA, USA, 2014.

38. Pachauri, S.; Rao, N.D. Gender impacts and determinants of energy poverty: Are we asking the right questions? Curr. Opin. Environ. Sustain. 2013, 5, 205-215.

39. Shankar, A.; Johnson, M.; Kay, E.; Pannu, R.; Beltramo, T.; Derby, E.; Harrell, S.; Davis, C.; Petach, H. Maximizing the benefits of improved cookstoves: Moving from acquisition to correct and consistent use. Glob. Health: Sci. Pract. 2014, 2, 268-274.

40. Sami, M.; Annamalai, K.; Wooldridge, M. Co-firing of coal and biomass fuel blends. Prog. Energ. Combust. Sci. 2001, 27, 171-214. 
41. Global Alliance for Clean Cookstoves. Available online: http://www.cleancookstoves.org (accessed on 2 October 2014).

42. Wang, X.; Westerdahl, D.; Wu, Y.; Pan, X.; Zhang, K.M. On-road emission factor distributions of individual diesel vehicles in and around Beijing, China. Atmos. Environ. 2010, 45, 503-513.

43. Gaines, L.; Vyas, A.; Anderson, J.L. Estimation of fuel use by idling commercial trucks. Transp. Res. Rec. 2006, 1983, 91-98.

44. Al-Mansour, F.; Zuwala, J. An evaluation of biomass co-firing in Europe. Biomass BioEnerg. 2010, 34, 620-629.

45. Climate and Clean Air Coalition. Available online: http://www.ccacoalition.org/ (accessed on 2 October 2014).

46. Fan, J.H.; Akimov, A.; Roca, E. Dynamic Hedge Ratio Estimations in the European Union Emissions Offset Credit Market. J. Clean. Prod. 2012, 42, 254-262.

47. Intercontinental exchange (ICE) Available online: www.theice.com (accessed on 29 November 2012).

48. Knopf, B.; Chen, Y.H.H.; de Cian, E.; Förster, H.; Kanudia, A.; Karkatsouli, I.; Keppo, I.; Koljonen, T.; Schumacher, K.; van Vuuren, D.P. Beyond 2020-Strategies and costs for transforming the European energy system. Clim. Chang. Econ. 2013, doi:10.1142/S2010007813400010.

49. Johansson, D.J.; Lucas, P.L.; Weitzel, M.; Ahlgren, E.O.; Bazaz, A.; Chen, W.; den Elzen, M.G.; Ghosh, J.; Grahn, M.; Liang, Q.M. Multi-model comparison of the economic and energy implications for China and India in an international climate regime. Mitig. Adapt. Strateg. Glob. Chang. 2014, doi:10.1007/s11027-014-9549-4.

50. Reynolds, C.C.O.; Kandlikar, M. Climate impacts of air quality policy: Switching to a natural gas-fueled public transportation system in New Delhi. Environ. Sci. Technol. 2008, 42, 5860-5865.

51. Jeuland, M.A.; Pattanayak, S.K. Benefits and costs of improved cookstoves: Assessing the implications of variability in health, forest and climate impacts. PLoS One 2012, 7, Article e30338.

52. Amacher, G.S.; Hyde, W.F.; Kanel, K.R. Household fuelwood demand and supply in Nepal's tarai and mid-hills: Choice between cash outlays and labor opportunity. World Dev. 1996, 24, 1725-1736.

53. Clean Clothes Campaign. Available online: http://www.cleanclothes.org (accessed on 6 October 2014).

54. Khandker, S.; Barnes, D.; Samad, H.A.; Minh, N.H. Welfare Impacts of Rural Electrification: Evidence from Vietnam; Asia Sustainable and Alternative Energy Program (ASTAE), Impact Evaluation series No. IE 38, Policy Research working paper No.WPS 5057; World Bank: Washington, DC, USA, 2009.

55. Institute of Sociology in Hanoi. Data Set: Impacts of Rural Electrification in Vietnam; Institute of Sociology: Hanoi, Vietnam, 2009.

56. U.S. Department of State. Available online: http://www.state.gov (accessed on 6 October 2014).

57. Levine, D.I.; Beltramo, T.; Blalock, G.; Cotterman, C. What Impedes Efficient Adoption of Products? Evidence from Randomized Variation in Sales Offers for Improved Cookstoves in Uganda; Working paper series No.WPS-014; Center for Effective Global Action: Berkeley, CA, USA, 2013.

58. Berndes, G.; Hansson, J.; Egeskog, A.; Johnsson, F. Strategies for 2nd generation biofuels in EU-Co-firing to stimulate feedstock supply development and process integration to improve energy efficiency and economic competitiveness. Biomass BioEnerg. 2010, 34, 227-236. 
59. Wang, X.; Tan, H.; Niu, Y.; Pourkashanian, M.; Ma, L.; Chen, E.; Liu, Y.; Liu, Z.; Xu, T. Experimental investigation on biomass co-firing in a $300 \mathrm{MW}$ pulverized coal-fired utility furnace in China. Proc. Combust. Inst. 2011, 33, 2725-2733.

60. Narayanan, K.V.; Natarajan, E. Experimental studies on cofiring of coal and biomass blends in India. Renew. Energ. 2007, 32, 2548-2558.

61. Cooke, P.A. Intrahousehold labor allocation responses to environmental good scarcity: A case study from the hills of Nepal. Econ. Dev. Cult. Chang. 1998, 46, 807-830.

62. Heltberg, R.; Arndt, T.C.; Sekhar, N.U. Fuelwood Consumption and Forest Degradation: A Household Model for Domestic Energy Substitution in Rural India. Land Econ. 2000, 76, 213-232.

63. Dewees, P.A. The woodfuel crisis reconsidered: Observations on the dynamics of abundance and scarcity. World Dev. 1989, 17, 1159-1172.

64. Linde-Rahr, M. Property Rights and Deforestation: The Choice of Fuelwood Source in Rural Viet Nam. Land Econ. 2003, 79, 217-234.

65. Cooke, P.; Köhlin, G.; Hyde, W.F. Fuelwood, forests and community management-Evidence from household studies. Environ. Dev. Econ. 2008, 13, 103-135.

66. Msuya, N.; Masanja, E.; Temu, A.K. Environmental Burden of Charcoal Production and Use in Dar es Salaam, Tanzania. J. Environ. Prot. 2011, 2, 1364-1369.

67. Hyde, W.F.; Amacher, G.S.; Magrath, W. Deforestation and forest land use: Theory, evidence, and policy implications. World Bank Res. Obs. 1996, 11, 223-248.

68. Foster, A.D.; Rosenzweig, M.R. Economic growth and the rise of forests. Q. J. Econ. 2003, 118, 601-637.

69. Van’t Veld, K.; Narain, U.; Gupta, S.; Chopra, N.; Singh, S. India's Firewood Crisis Re-Examined; Resources for the Future: Washington, DC, USA, 2006.

70. Rudel, T.K.; Coomes, O.T.; Moran, E.; Achard, F.; Angelsen, A.; Xu, J.; Lambin, E. Forest transitions: Towards a global understanding of land use change. Globle Environ. Chang. 2005, 15, 23-31.

71. Meyfroidt, P.; Lambin, E.F. Global Forest Transition: Prospects for an End to Deforestation. Annu. Rev. Environ. Resour. 2011, 36, 343-371.

(C) 2014 by the authors; licensee MDPI, Basel, Switzerland. This article is an open access article distributed under the terms and conditions of the Creative Commons Attribution license (http://creativecommons.org/licenses/by/4.0/). 